\title{
Rice Stripe Mosaic Virus-Encoded P4 Is a Weak Suppressor of Viral RNA Silencing and Is Required for Disease Symptom Development
}

\author{
Chao Zhang, Dong Chen, Guoyi Yang, Xiyuan Yu, and Jianguo $\mathrm{Wu}^{\dagger}$ \\ Vector-borne Virus Research Center, State Key Laboratory of Ecological Pest Control for Fujian and Taiwan Crops, Institute of \\ Plant Virology, College of Plant Protection, Fujian Agriculture and Forestry University, Fuzhou, 350002, China \\ Accepted 11 December 2019.
}

\begin{abstract}
Viral suppressors of RNA silencing (VSRs) are a cluster of viral proteins that have evolved to counteract eukaryotic antiviral RNA silencing pathways, thereby contributing to viral pathogenicity. In this study, we revealed that the matrix protein $P 4$ encoded by rice stripe mosaic virus (RSMV), which is an emerging cytoplasmic rhabdovirus, is a weak RNA silencing suppressor. By conducting yeast two-hybrid, bimolecular fluorescence complementation, and subcellular colocalization assays, we proved that $P 4$ interacts with the rice endogenous suppressor of gene silencing 3 (OsSGS3). We also determined that $P 4$ overexpression has no effect on $O S S G S 3$ transcription. However, P4 can promote the degradation of OsSGS3 via ubiquitination and autophagy. Additionally, a potato virus $\mathrm{X}$ based expression system was used to confirm that $P 4$ enhances the development of mosaic symptoms on Nicotiana benthamiana leaves by promoting hydrogen peroxide accumulation but not cell death. To verify whether $P 4$ is a pathogenicity factor in host plants, we generated transgenic $P$ 4-overexpressing rice plants that exhibited disease-related developmental defects including decreased plant height and excessive tillering. Our data suggest that RSMV-encoded P4 serves as a weak VSR that inhibits antiviral RNA silencing by targeting OsSGS3.
\end{abstract}

Keywords: P4, RNA silencing, rice stripe mosaic virus (RSMV), Suppressor of gene silencing 3

In plants, RNA silencing functions as a primary immune defense against viruses, which are recognized as invading nucleic acids by a host surveillance mechanism (Baulcombe 2004; Jiang et al. 2012; Li and Wang 2019). The viral doublestranded RNAs (dsRNAs) serve as signature molecules that initiate antiviral RNA silencing (Ding and Voinnet 2007). The following two non-mutually exclusive models are believed to

Chao Zhang and Dong Chen contributed equally to this work.

${ }^{\dagger}$ Corresponding author: J. Wu; wujianguo81@126.com

Funding: This work was supported by grants from the National Natural Science Foundation of China (31722045, 31701757, 31871934, and 31772128) and the Fok Ying-Tong Education Foundation, China (161024).

*The $\boldsymbol{e}$-Xtra logo stands for "electronic extra" and indicates that three supplementary figures and one supplementary table are published online.

The author(s) declare no conflict of interest.

๑) 2020 The American Phytopathological Society be required for the production of viral dsRNAs: i) internal pairing of viral RNA molecules, which can occur either as intermediates during viral replication and transcription (RNA viruses) or via converging bidirectional transcription (DNA viruses) (Ahlquist 2006; Donaire et al. 2009; Molnár et al. 2005), ii) de novo synthesis by the host suppressor of gene silencing 3 (SGS3) and RNA-dependent RNA polymerase 6 (RDR6) complex, with viral genomic fragments as the template (Donaire et al. 2008; Kasschau et al. 2007; Qi et al. 2009). Previous analyses of Arabidopsis thaliana loss-of-function Dicer-like (DCL) mutants indicated that viral dsRNAs are hierarchically processed by the host DCL proteins into small 20to 24-nucleotide (nt) RNA duplexes called virus-derived small interfering RNAs (vsiRNAs) (Bouché et al. 2006; Deleris et al. 2006; Blevins et al. 2006; Du et al. 2007). The Arabidopsis thaliana genome has four DCL genes (Henderson et al. 2006; Margis et al. 2006). DCL4, the primary sensor of viral dsRNAs, produces 21-nt vsiRNAs, which is the most common length in virus-infected tissues. Moreover, DCL2 functions as a surrogate of DCL4 and generates 22-nt vsiRNAs. In the absence of DCL4 and DCL2, DCL3 produces 24-nt vsiRNAs by cleaving viral dsRNAs. A previous study detected small amounts of vsiRNAs in $\mathrm{dcl} 2 \mathrm{dcl} 3 \mathrm{dcl} 4$ Arabidopsis thaliana loss-of-function triple mutants infected with turnip mosaic virus, implying that DCL1 can access viral dsRNA and contribute minimally to vsiRNA production (Garcia-Ruiz et al. 2010). The vsiRNAs are at the core of plant-virus interactions and are incorporated by Argonaute (AGO) proteins, which are the key components of the RNA-induced silencing complex (RISC) that exhibit RNase activity and catalyze the cleavage of homologous viral RNAs (Carbonell and Carrington 2015; Llave 2010). Antiviral RNA silencing can be amplified in a SGS3/RDR6-dependent manner, which results in the production of secondary vsiRNAs (Kumakura et al. 2009; Peragine et al. 2004; Yoshikawa et al. 2013). Many studies indicated that plants with aberrant RNA silencing components exhibit increased susceptibility to viral infections, providing further evidence that RNA silencing is crucial for the targeting of plant viruses by host plants (Simón-Mateo and Garcia 2011). For example, a natural variant or loss-of-function mutations to host RDR proteins lead to the hyper-susceptibility to viral infections (Schwach et al. 2005; Xie et al. 2001; Yang et al. 2004).

Consistent with an antiviral role for RNA silencing, many plant viruses have evolved to encode at least one viral suppressor of RNA silencing (VSR) (Csorba et al. 2015; Daròs 2017; Wu et al. 2010b). An earlier investigation proved that VSR activity is detectable during assays with artificial RNA silencing induced by exogenous dsRNA or an overexpressed 
sense RNA transgene (Li and Ding 2006). A green fluorescent protein (GFP)-based transient expression assay involving $\mathrm{Ni}$ cotiana benthamiana was developed and extensively applied as one of the three major approaches for identifying functional VSRs (Johansen and Carrington 2001; Llave et al. 2000). Additionally, VSRs suppress RNA silencing at virtually all steps. Specifically, they limit the vsiRNA generation rate via their dsRNA and siRNA binding activities and the inhibition of DCL activities. Moreover, they suppress cell-autonomous silencing amplification and systemic signal transmissions in distal tissues by targeting SGS3/RDR6 complexes and they inactivate AGO proteins by interacting with them or destabilizing them. Most VSRs suppress antiviral RNA silencing through dsRNA and siRNA sequestration (Csorba et al. 2015; Mérai et al. 2006). The tombusviral p19 protein is a well-characterized sizedependent siRNA binder that sequesters the silencinggenerated 21- to 25-nt dsRNAs and 21-nt synthetic dsRNAs with 2-nt 3' overhanging ends (Silhavy et al. 2002). Previous studies indicated that V2 of tomato yellow leaf curl virus (Glick et al. 2008), TGB1 of plantago asiatica mosaic virus (Okano et al. 2014), and the Class 1 RNase III endoribonuclease (RNase 3) of sweet potato chlorotic stunt virus (Weinheimer et al. 2016) target SGS3 to decrease the production of secondary vsiRNAs, thereby blocking the amplification of the antiviral RNA silencing signal and attenuating plant antiviral immunity. The $2 b$ protein encoded by cucumber mosaic virus was the first VSR confirmed to arrest the assembly of a functional RISC through an interaction with AGO (Zhang et al. 2006). The tomato ringspot virus coat protein (CP), which is another well-documented VSR, binds to AGO1 to suppress its translational inhibitory activity and to enhance AGO1 degradation through autophagy (Karran and Sanfaçon 2014).

The majority of VSRs encoded by rice viruses have been determined through a GFP-based transient expression assay. To date, P1 of rice yellow mottle virus (Lacombe et al. 2010), P2 and P3 of rice stripe virus (RSV) (Du et al. 2011; Xiong et al. 2009), NS3 of rice hoja blanca tenuivirus (Hemmes et al. 2009), P5 of rice grassy stunt virus (RGSV) (Zhang et al. 2015), P6 of rice yellow stunt rhabdovirus (RYSV) (Guo et al. 2013), Pns6 of rice ragged stunt virus (RRSV) (Wu et al. 2010a), S6 of rice black-streak dwarf virus and southern rice black-streak dwarf virus (Lu et al. 2011; Zhang et al. 2005), Pns10 of rice dwarf virus (RDV) (Ren et al. 2010), and Pns11 (Liu et al. 2008) and Pns12 (Wu et al. 2011) of rice gall dwarf virus (RGDV) have been confirmed as suppressors of antiviral RNA silencing. However, the mechanism underlying the activity of only a few VSRs have been preliminarily uncovered without genetic evidence. For example, RDV Pns10 suppresses local and systemic RNA silencing triggered by sense mRNA by disrupting the perception of silencing signals in recipient tissues, binding double-stranded siRNAs with 2-nt 3' overhangs, and downregulating RDR6 expression (Ren et al. 2010). Additionally, RYSV P6 suppresses systemic RNA silencing by blocking RDR6-mediated secondary siRNA synthesis (Guo et al. 2013). The RSV-encoded dimeric P3 is a dsRNA-binding protein that recognizes a minimum of $9 \mathrm{bp}$ in a size-independent manner and can bind to long dsRNAs with two or more copies to finally suppress antiviral RNA silencing (Shen et al. 2010).

Rice stripe mosaic virus (RSMV) is a recently reported cytoplasmic rhabdovirus adversely affecting rice production in the Guangdong province, China, although the incidence of the corresponding disease is currently low (Yang et al. 2017). Rice plants infected with RSMV exhibit distinct symptoms, including yellow stripes, mosaic patterns, and twisted leaf tips. Moreover, RSMV is transmitted by the leafhoppers Recilia dorsalis and Nephotettix virescens in a persistent-propagative manner (Yang et al. 2017; Zhao et al. 2019). A comparison of the amino acid sequences of the proteins produced by RSMV and other known rhabdoviruses suggests that the RSMV antigenome comprises seven open reading frames (ORFs) (i.e., ORF1 through ORF7). The proteins encoded by ORF1, ORF2, ORF4, ORF5, and ORF7 are homologous to the nucleocapsid protein $(\mathrm{N})$, phosphoprotein $(\mathrm{P})$, matrix $(\mathrm{M})$ protein, glycoprotein $(\mathrm{G})$, and large polymerase protein (L) of known rhabdoviruses, respectively. In contrast, ORF3 and ORF6 are considered to encode two nonstructural proteins. However, the RSMV proteins have not been functionally characterized.

In the present study, we determined that the RSMV-encoded matrix protein $\mathrm{P} 4$ is a weak VSR. We proved that $\mathrm{P} 4$ can directly interact with rice SGS3 (OsSGS3), ultimately resulting in the degradation of OsSGS3 in a ubiquitination- and autophagydependent manner. However, OsSGS3 transcript accumulation is unaffected by $P 4$ overexpression. We also confirmed that $\mathrm{P} 4$ is critical for viral pathogenicity, either in a heterologous potato virus $\mathrm{X}$ (PVX) expression system or in host plants. These findings imply that RSMV P4 suppresses host RNA silencing, possibly by destabilizing SGS3 to overcome plant antiviral immunity.

\section{RESULTS}

\section{RSMV P4 suppresses local RNA silencing} in $N$. benthamiana plants.

To determine whether RSMV encodes a suppressor of RNA silencing, $N$. benthamiana $16 \mathrm{c}$ leaves were infiltrated with a culture coexpressing either 35S-ssGFP (single-stranded GFP) or 35S-dsGFP (double-stranded GFP) and RSMV ORFs. At 3 days postinfiltration (dpi), GFP fluorescence was undetectable in the leaf tissues infiltrated with 35S-ssGFP+E.V. (empty vector), 35S-ssGFP+P4-Myc, and 35S-ssGFP+P $\Delta 4-M y c$. Weak fluorescence was detected in the leaf tissues infiltrated with 35S-dsGFP+P4-Myc, whereas fluorescence was not detected in the leaves infiltrated with $35 \mathrm{~S}-\mathrm{dsGFP}+\mathrm{E}$.V. or $35 \mathrm{~S}-\mathrm{dsGFP}+\mathrm{P} \Delta 4-$ Myc. In contrast, relatively strong fluorescence was detected in leaf tissues infiltrated with 35S-ssGFP+HC-Pro or 35SdsGFP+HC-Pro (Fig. 1A). The production of P4 was confirmed in a Western blot assay (Fig. 1B and C). Additionally, GFP mRNA accumulated slightly more in leaves with 35SdsGFP+P4-Myc than in leaves with 35S-dsGFP+E.V. or 35SdsGFP+P $\Delta 4-M y c$ (Fig. 1D). We also assessed whether other RSMV proteins (but not P7, which is a putative RDR) function as VSRs in GFP-based transient expression assays involving transgenic $N$. benthamiana $16 \mathrm{c}$ leaves. These proteins did not suppress the GFP silencing induced by either ssGFP or dsGFP (Supplementary Fig. S1). These results revealed that the RSMVencoded P4 can function locally as a weak VSR.

\section{P4 interacts with rice SGS3.}

Considering that many VSRs inhibit antiviral RNA silencing by associating with SGS3, we examined whether P4 can directly interact with rice SGS3 (OsSGS3), which is encoded by a gene that is highly homologous to Arabidopsis thaliana SGS3 (Du et al. 2011), by performing yeast two-hybrid (Y2H), bimolecular fluorescence complementation (BiFC), and subcellular colocalization assays. The $\mathrm{Y} 2 \mathrm{H}$ assay revealed that the coproduction of $\mathrm{P} 4$ and OsSGS3 can rescue the growth of yeast cells on quadruple dropout (QDO) medium and restore $\beta$-galactosidase activity (Fig. 2A). Neither P4 nor OsSGS3 exhibited any auto-activation or auto-binding activity. Furthermore, the interaction between P4 and OsSGS3 was confirmed by the BiFC assay (Fig. 2B). To determine the subcellular localization of RSMV P4 and OsSGS3, yellow fluorescent protein (YFP)-tagged OsSGS3 (YFP-OsSGS3) and cyan fluorescent protein (CFP)-tagged P4 (CFP-P4) were transiently produced 
individually and together in N. benthamiana epidermal cells. Both RSMV P4 and OsSGS3 localized within nuclei (Fig. 2C). Their colocalization in the nuclei of $N$. benthamiana epidermal cells was confirmed based on the monitoring of granule-like foci of YFP fluorescence in BiFC and subcellular colocalization assays (Fig. 2C). In contrast, the subcellular localization patterns of five other RSMV proteins differed from that of P4 (Supplementary Fig. S2). These data indicated that P4 can interact with OsSGS3 in the nuclei of $N$. benthamiana epidermal cells.

\section{P4 destabilizes rice SGS3.}

Previous studies on VPg proved that this potyvirus-encoded VSR mediates the degradation of SGS3 via ubiquitination and autophagy (Cheng and Wang 2016). To test whether P4 can degrade SGS3, Myc-OsSGS3 was transiently produced with gradually increasing amounts of Flag-tagged P4 (Flag-P4) in $N$. benthamiana leaves. Western blotting with anti-Myc antibodies at 2 dpi revealed that the accumulation of OsSGS3 decreased considerably with gradually increasing Flag-P4 contents (Fig. 3A). In contrast, the abundance of GFP did not
A

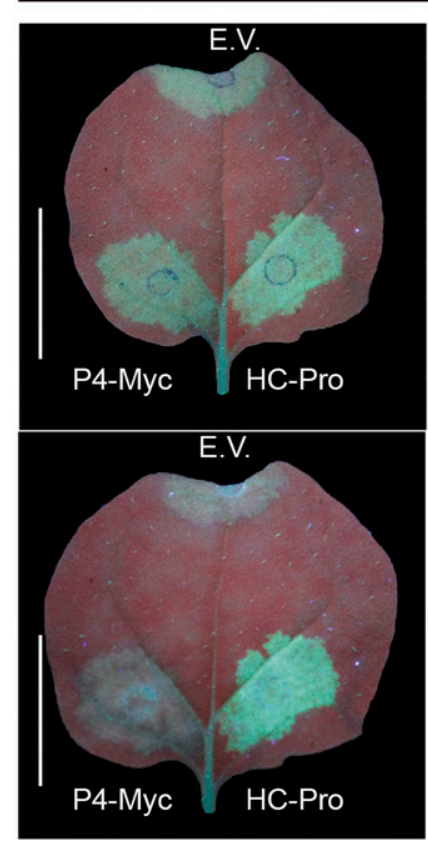

35S-ssGFP

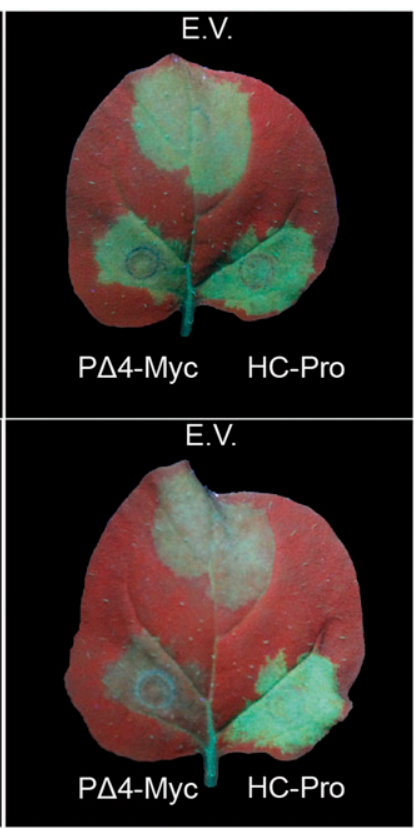

35S-dsGFP

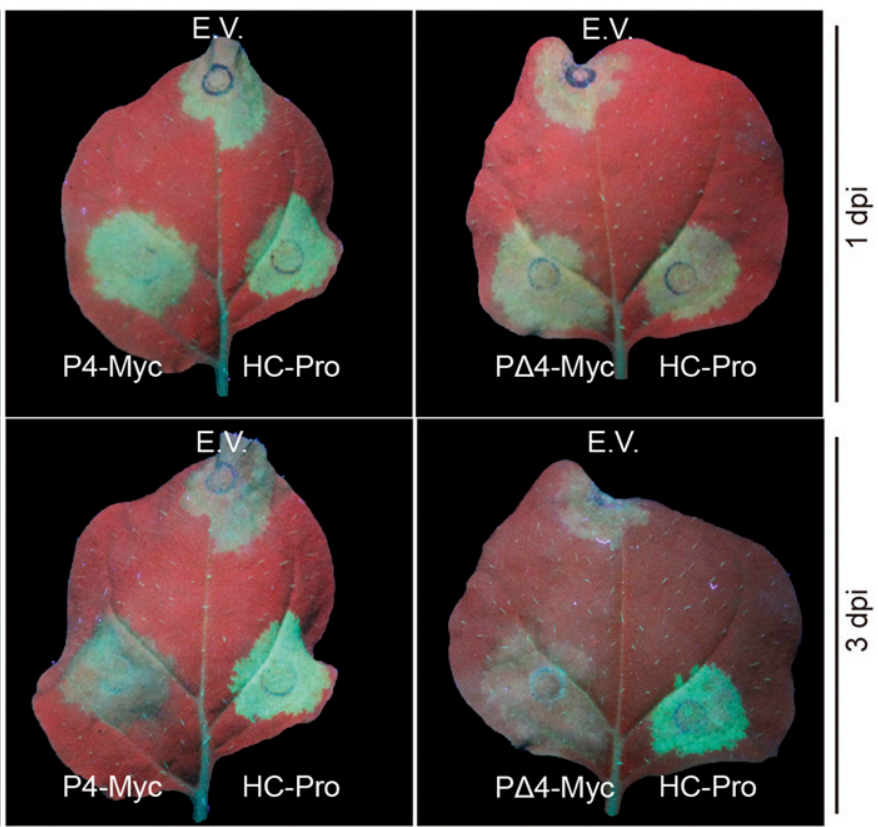

B

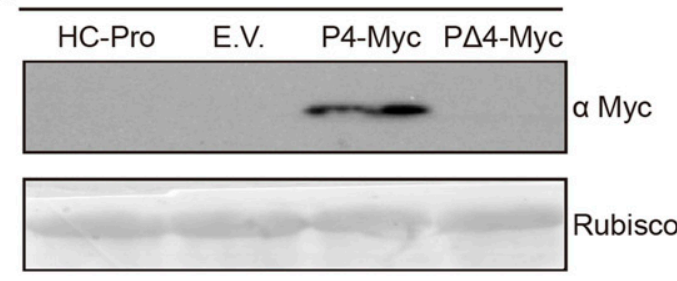

C
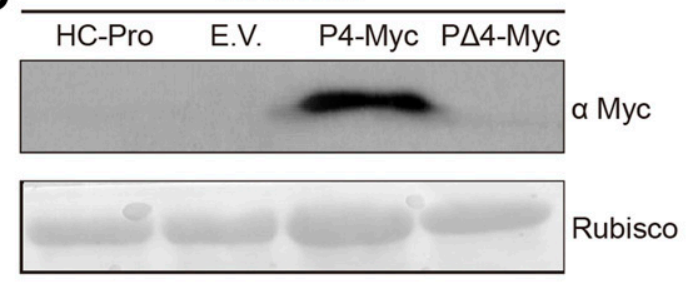

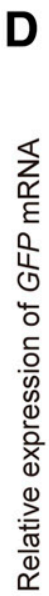

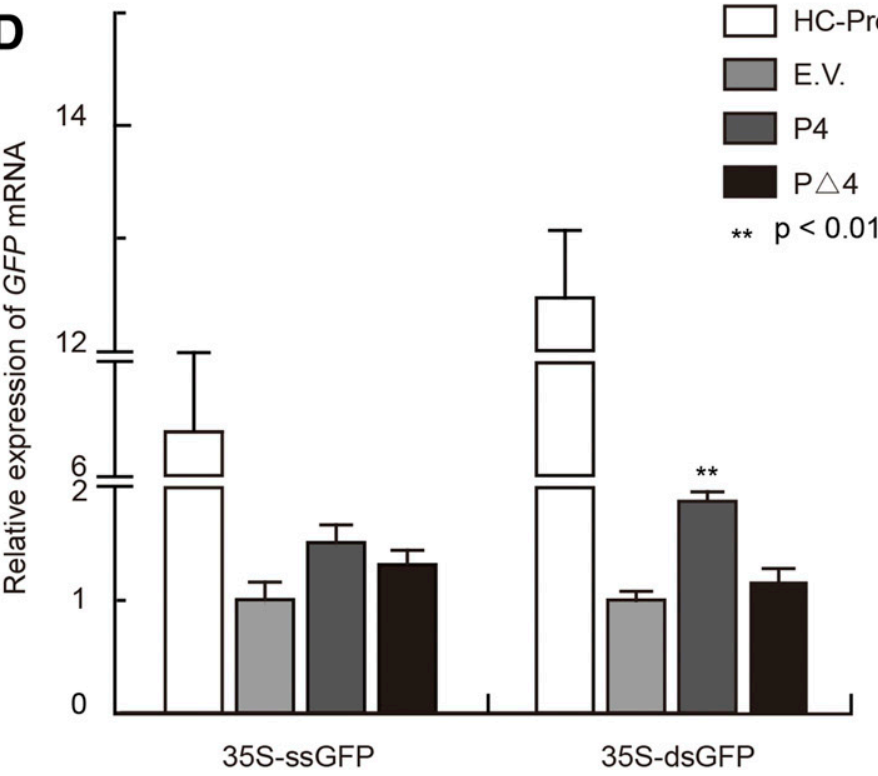

Fig. 1. Identification of $\mathrm{P} 4$ as a rice stripe mosaic virus (RSMV) viral suppressor of RNA silencing. A, A transient expression assay involving Nicotiana benthamiana line 16c leaves revealed the suppressive effect of RSMV P4 on the local silencing caused by the single-stranded green fluorescent protein ( $G F P$ ) RNA (ssGFP) or the double-stranded GFP RNA (dsGFP). Leaves were infiltrated with Agrobacterium tumefaciens cells carrying different constructs, as indicated above the photographs. Leaves were photographed at 1 and 3 days postinfiltration. B and $\mathbf{C}$, Western blot analysis of the accumulation of P4-Myc in leaves infiltrated with A. tumefaciens harboring the indicated constructs. Ponceau staining of the large RUBISCO subunit served as a loading control. D, Quantitative real time PCR analysis of GFP expression in N. benthamiana line 16c leaves infiltrated with A. tumefaciens carrying GFP. Similar results were obtained in three biological repeats. Double askterisks (**) indicate $P<0.01$, according to the $t$ test. Error bars represent the standard deviation of biological repeats. Scale bar $=2 \mathrm{~cm}$. 
decrease when it was coexpressed with Flag-P4. Actin was used as a loading control. The decrease in OsSGS3 abundance mediated by $\mathrm{P} 4$ can be rescued by infiltrating cells with MG132 (proteasome inhibitor) and E64d (autophagy inhibitor). These results suggested that $\mathrm{P} 4$ may enhance the degradation of OsSGS3 by directly interacting with it, ultimately disrupting the amplification of the antiviral RNA silencing signal. To determine whether the targeting of RNA silencing components by $\mathrm{P} 4$ occurs at the transcriptional level, we conducted a quantitative real-time PCR (qRT-PCR) assay to verify the transcriptional inhibition of certain RNA silencing components due to $P 4$ overexpression. We observed that the OsSGS3 transcript level was not regulated by $\mathrm{P} 4$ (Fig. 3B). Other RNA interferenceassociated genes were also not significantly affected by $P 4$ overexpression (Fig. 3C to G). Collectively, our findings suggested P4 may influence antiviral RNA silencing through the destabilization of SGS3 but has no effect on SGS3 transcription.

\section{P4 enhances PVX virulence}

by boosting the hypersensitive response.

We used a PVX-based expression assay to analyze the role of RSMV P4 related to viral pathogenicity. The recombinant PVX-P4 virus was infiltrated into $N$. benthamiana leaves. Additionally, leaves infiltrated with PVX with no insert and $\beta C 1$, which is a well-documented VSR, were used as negative and positive controls, respectively. Disease symptom development on the agro-infiltrated plants was monitored daily (Table 1). Plants infiltrated with PVX-P4 exhibited the early onset of virus-induced mosaic symptoms, with a few chlorotic plaques on the first three systemic leaves (SLs) (SL1, SL2, and SL3) at $5 \mathrm{dpi}$, whereas the PVX-inoculated plants had relatively weak mosaic symptoms that mostly developed on the first two SLs (Fig. 4A). At 12 dpi, the leaves infiltrated with PVX-P4 showed typical systemic mosaic symptoms, which were more severe than the symptoms on the leaves infiltrated with PVX. Our reverse transcription PCR results indicated that $P 4$ was expressed in the viral progeny (Fig. 4B). Moreover, we compared the accumulation of PVX CP transcripts in the leaves infiltrated with PVX, PVX-P4, and PVX- $\beta C 1$ at 5 dpi in a qRT$\mathrm{PCR}$ assay. The resulting data indicated the PVX CP transcript level was considerably higher in PVX-P4-infected plants than in the PVX-infected counterparts (Fig. 4C). These results implied that, in the presence of $\mathrm{P} 4$, severe disease symptoms are due to the increasing accumulation of PVX.

To investigate whether the increased systemic necrosis induced by PVX-P4 is accompanied by biochemical features that are characteristic of hypersensitive responses, the accumulation of $\mathrm{H}_{2} \mathrm{O}_{2}$ and cell death were examined in $3,3^{\prime}$-diaminobenzidine (DAB) and trypan blue staining assays, respectively. At $12 \mathrm{dpi}$, the upper noninfiltrated leaves of plants infected with PVX,
A

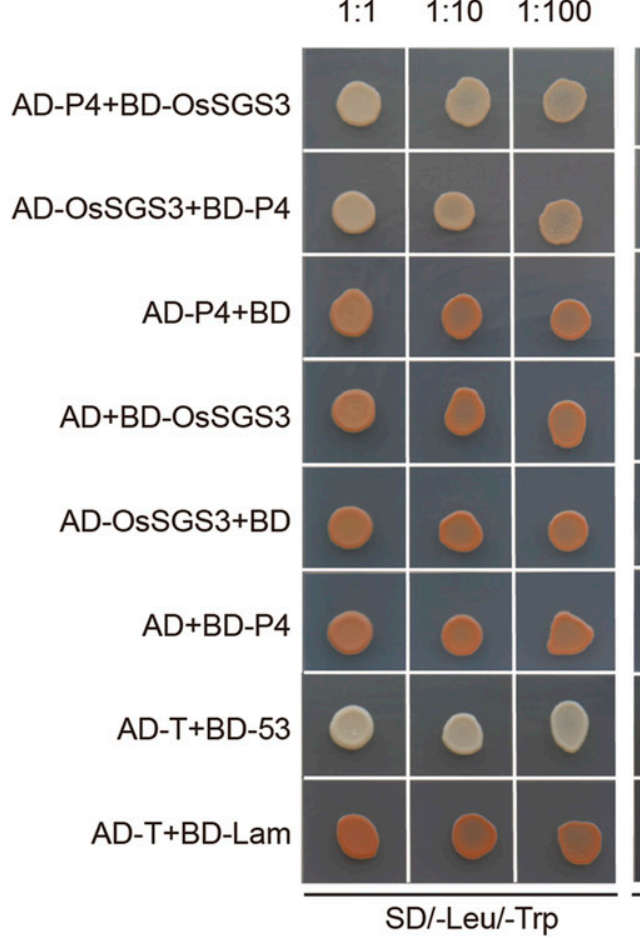

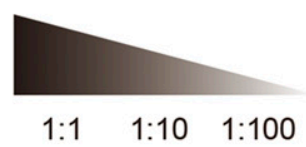
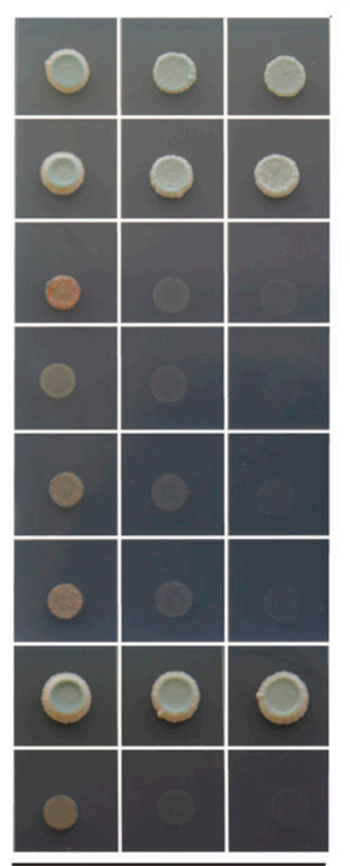

$\mathrm{SD} /$-Leu/-Trp/

-Ade/-His+X-a-Gal

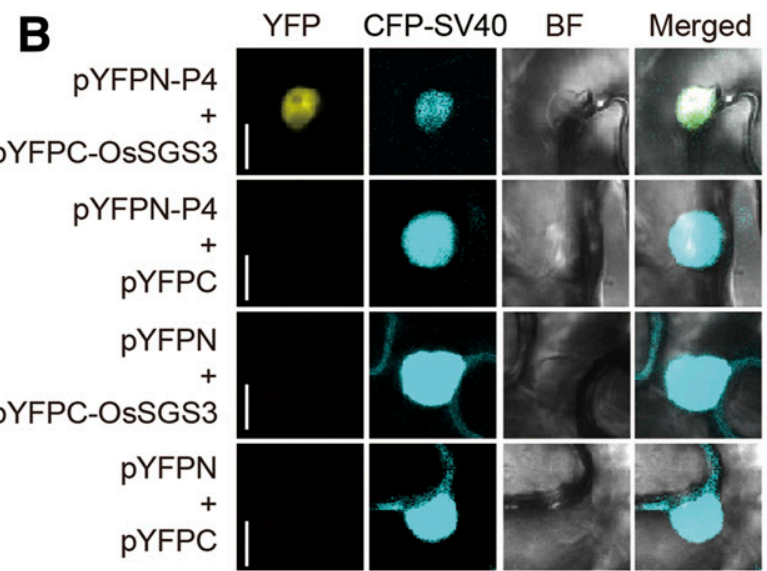

C

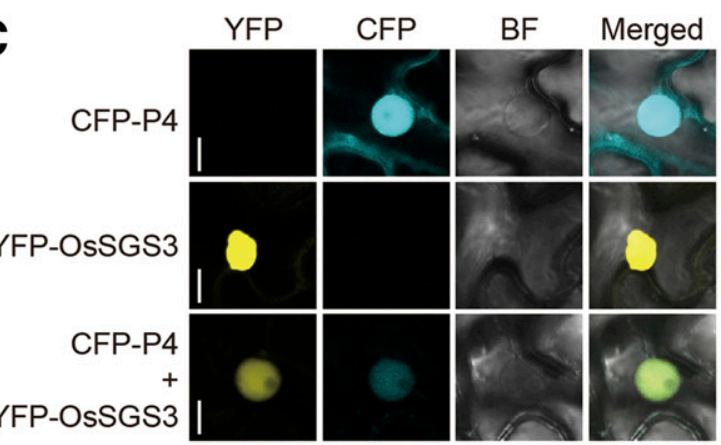

Fig. 2. Rice stripe mosaic virus (RSMV) P4 interacts with OsSGS3. A, Yeast two-hybrid assays were conducted to confirm the interaction between RSMV-P4 and OsSGS3. The indicated plasmid pairs presented on the left side of the panel were inserted together into the Y2HGold cells, after which the cotransformants were spread onto the agar-solidified double dropout SD/-Leu/-Trp selection medium and the quadruple dropout SD/-Ade/-His/-Leu/-Trp (QDO) selection medium containing X- $\alpha$-gal. Yeast cells cotransformed with AD-P4/BD, AD/BD-OsSGS3, AD-OsSGS3/BD, AD/BD-P4, and pGBKT7-Lam/pGADT7-T were used as negative controls, whereas cells with AD-T/BD-53 were used as the positive control. B, The interaction between P4 and OsSGS3 was confirmed by bimolecular fluorescence complementation analysis. Nicotiana benthamiana leaves were infiltrated with Agrobacterium tumefaciens cells carrying pYFPNP4/pYFPC-OsSGS3. The $N$. benthamiana leaves infiltrated with A. tumefaciens cells carrying pYFPN-P4/pYFPC, pYFPN-/pYFPC-OsSGS3, and pYFPN/ pYFPC served as negative controls. The nucleus was labeled by cotransfecting cells with the CFP-SV40 construct. C, The P4 and OsSGS3 localization patterns were analyzed in a subcellular localization assay involving $N$. benthamiana cells. The yellow or cyan fluorescence indicates the localization of OsSGS3-YFP or P4-CFP, respectively, in the nucleus of $N$. benthamiana epidermal cells. The fluorescence was monitored by confocal microscopy at 2 days postinfiltration. The experiments were repeated more than three times with similar results. Scale bars $=15 \mu \mathrm{m}$. 
PVX-P4, and PVX- $\beta C 1$ were analyzed by DAB staining. In the presence of $\mathrm{H}_{2} \mathrm{O}_{2}$, DAB is polymerized to produce a deep brown color that can be visualized after clearing the tissue with ethanol. The PVX-P4-infected leaves accumulated large amounts of $\mathrm{H}_{2} \mathrm{O}_{2}$ (Supplementary Fig. S3A). The upper PVX-P4-infected leaves of $N$. benthamiana plants were treated with trypan blue at $12 \mathrm{dpi}$, to screen for dead cells. The leaves were only lightly stained with no significant differences among the leaves infected with PVX, PVX-P4, and PVX- $\beta C 1$, suggesting P4 does not induce cell death (Supplementary Fig. S3B). These results confirmed that $\mathrm{P} 4$ produced from a PVX vector increases the $\mathrm{H}_{2} \mathrm{O}_{2}$ content of leaf cells.

These data suggested that RSMV P4 can promote PVX pathogenicity by enhancing PVX accumulation and induce severe disease symptoms via increasing $\mathrm{H}_{2} \mathrm{O}_{2}$ contents.

\section{Transgenic rice plants overexpressing P4 exhibit} abnormal phenotypes.

To further verify the pathogenicity of RSMV-encoded P4 in rice, we generated transgenic rice plants carrying RSMV P4
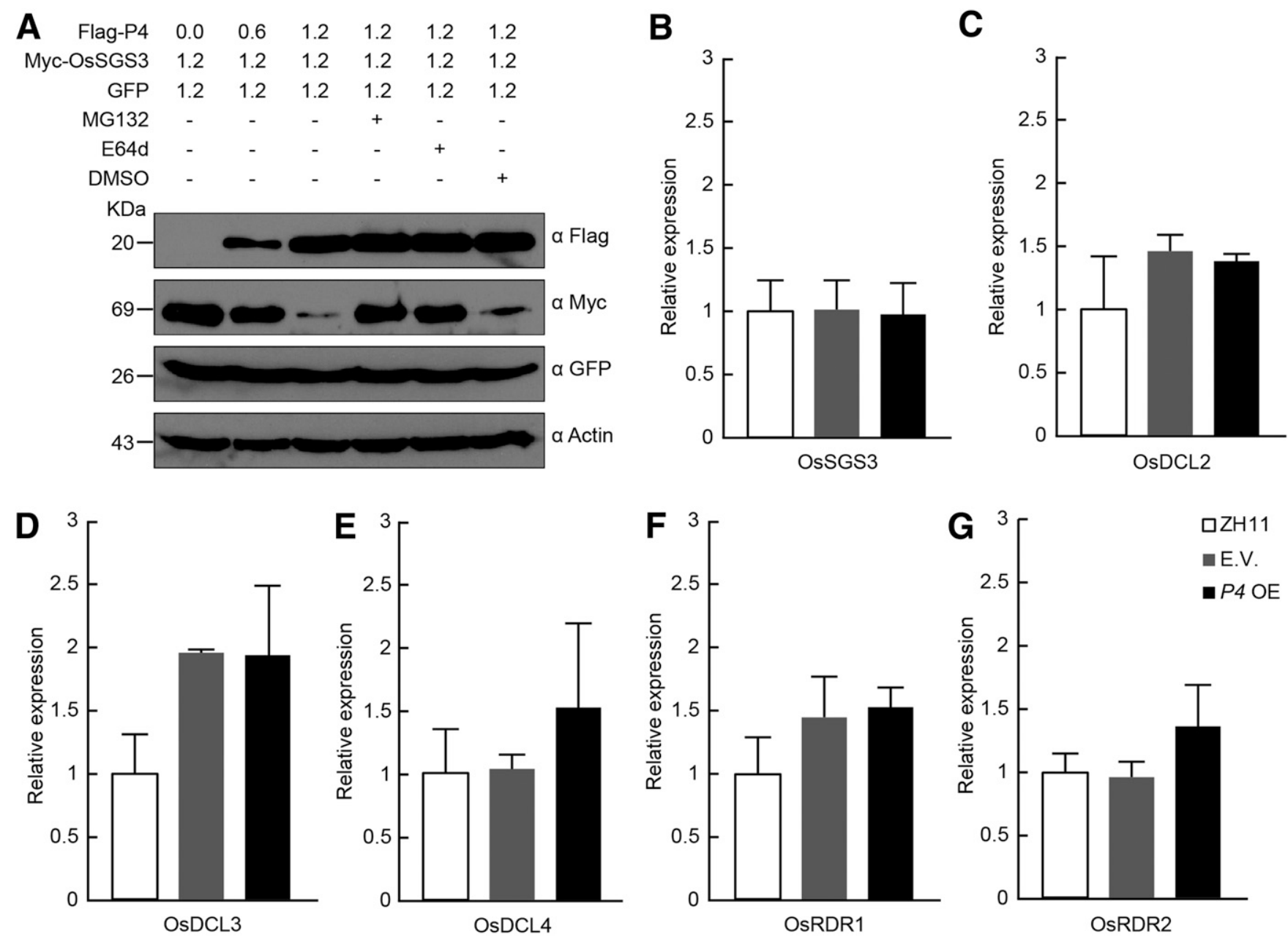

Fig. 3. Rice stripe mosaic virus $\mathrm{P} 4$ destabilizes OsSGS3 but does not affect the transcription of OsSGS3, which is a homolog of AtSGS3. A, The degradation of OsSGS3 was promoted by Flag-P4. Myc-OsSGS3 was transiently coexpressed with gradually increasing Flag-P4 concentrations in Nicotiana benthamiana leaf cells. Proteins were extracted from samples collected at 2 days postinfiltration (dpi). Monoclonal antibodies against the Flag-tag and Myc-tag were used to detect the accumulation of P4 and OsSGS3, respectively. Additionally, green fluorescent protein (GFP) served as a negative control, whereas actin was used as a loading control. The infiltrated leaf areas were treated with MG132 (a proteasome inhibitor) and E64d (an autophagy inhibitor) and dimethyl sulfoxide (DMSO) was injected as a control. Specifically, MG132, E64d, and DMSO were injected into the leaf tissues at $12 \mathrm{~h}$ before samples were collected. B to G, The relative expression levels of $O s S G S 3$ and other vital factors involved in the antiviral RNA interference pathway in ZH11, E.V., and P4-overexpressing lines were compared in a quantitative real-time PCR assay. Similar results were obtained in three biological repeats. Error bars represent the standard deviation of biological repeats.

Table 1. Summary of agroinfiltration in three independent experiments

\begin{tabular}{|c|c|c|c|c|c|c|}
\hline \multirow[b]{2}{*}{ Construct } & \multicolumn{5}{|c|}{ Disease symptoms } & \multirow[b]{2}{*}{ No. diseased/tota } \\
\hline & 3 dpi & 4 dpi & 5 dpi & 8 dpi & 12 dpi & \\
\hline $\begin{array}{l}\text { Potato virus } \\
\mathrm{X}(\mathrm{PVX})\end{array}$ & No symptoms & No symptoms & $\begin{array}{l}\text { Systemic mosaic leaf } \\
\text { without chlorosis }\end{array}$ & $\begin{array}{l}\text { Systemic mosaic leaf and } \\
\text { chlorosis }\end{array}$ & $\begin{array}{l}\text { Systemic mosaic leaf } \\
\text { and chlorosis }\end{array}$ & $11 / 12,10 / 12,12 / 12$ \\
\hline PVX-P4 & No symptoms & $\begin{array}{l}\text { Systemic } \\
\text { mosaic leaf }\end{array}$ & $\begin{array}{l}\text { Systemic mosaic leaf } \\
\text { with slight chlorosis }\end{array}$ & $\begin{array}{l}\text { Systemic obvious mosaic } \\
\text { leaf and chlorosis }\end{array}$ & $\begin{array}{l}\text { Systemic severe mosaic } \\
\text { leaf and chlorosis }\end{array}$ & $11 / 12,11 / 12,12 / 12$ \\
\hline$P V X-\beta C 1$ & $\begin{array}{l}\text { Systemic } \\
\text { mosaic leaf }\end{array}$ & $\begin{array}{l}\text { Systemic } \\
\text { mosaic leaf }\end{array}$ & $\begin{array}{l}\text { Systemic mosaic leaf } \\
\text { with obvious chlorosis }\end{array}$ & $\begin{array}{l}\text { Systemic severe crinkle, } \\
\text { mosaic leaf and chlorosis }\end{array}$ & $\begin{array}{l}\text { Systemic severe crinkle, } \\
\text { mosaic leaf and chlorosis }\end{array}$ & $12 / 12,12 / 12,12 / 12$ \\
\hline
\end{tabular}


under the control of the rice Actinl promoter in the ZH11 background. Transgenic $P 4$-overexpressing lines \#1 and \#2 (P4 OE \#1 and P4 OE \#2, respectively) were obtained (Fig. 5A). $P 4$ expression in the transgenic lines was confirmed by reverse transcription PCR and a Western blot with the anti-P4 polyclonal antibody (Fig. 5B). All transgenic lines exhibited abnormal phenotypes, including mild stunted growth and slightly increased tillering. Additionally, the P4-overexpressing plants were $73 \mathrm{~cm}$ tall, making them shorter than the ZH11 wild-type plants $(92 \mathrm{~cm})$ and the transgenic plants carrying the E.V.
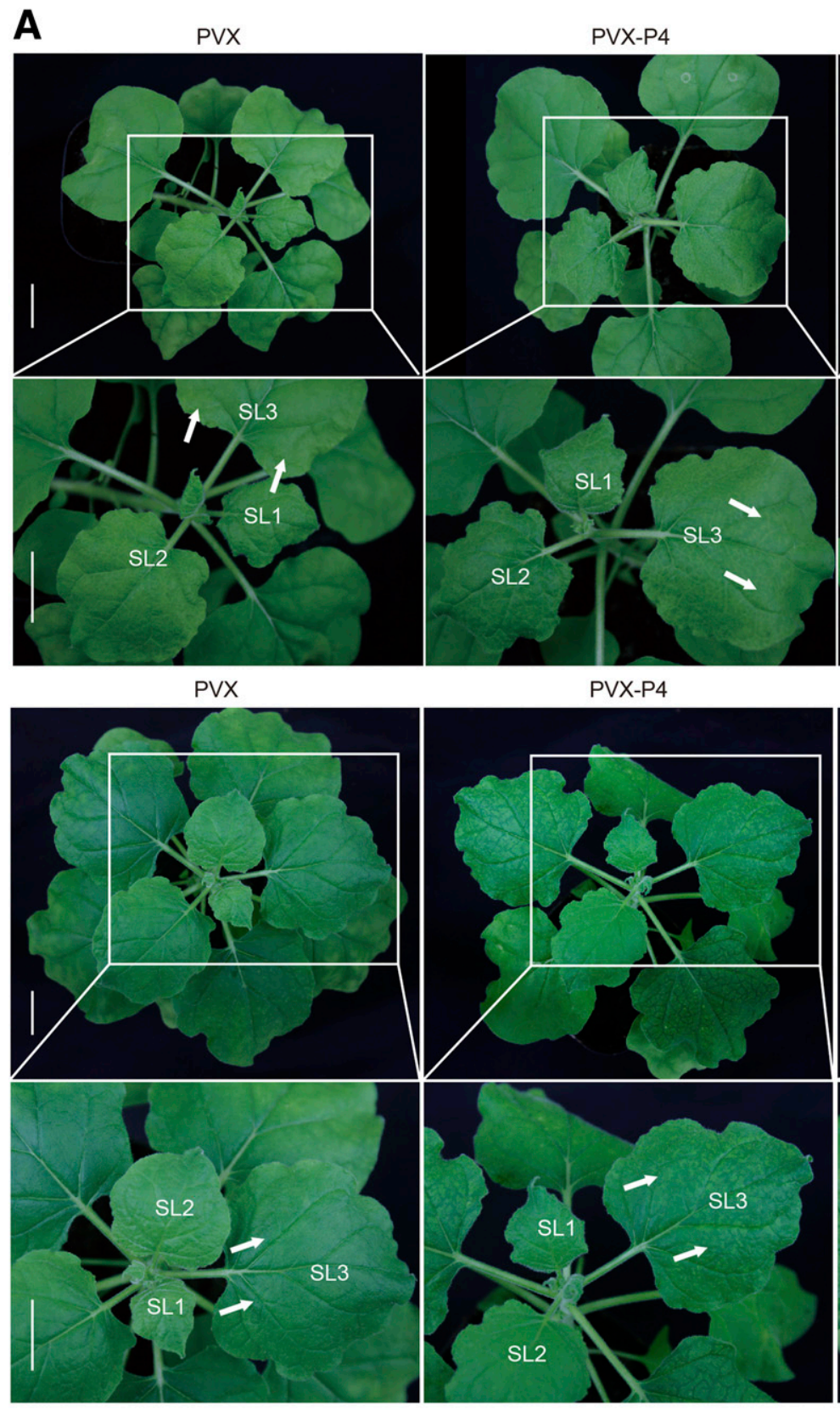

PVX-P4

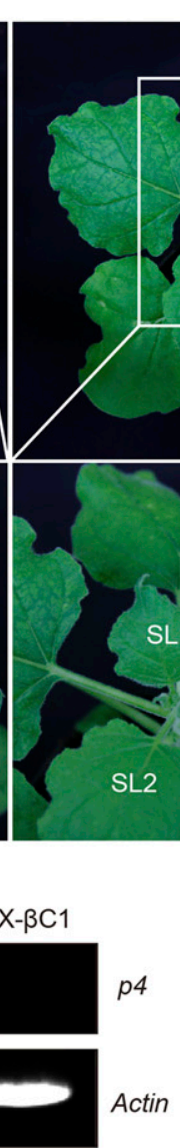

B

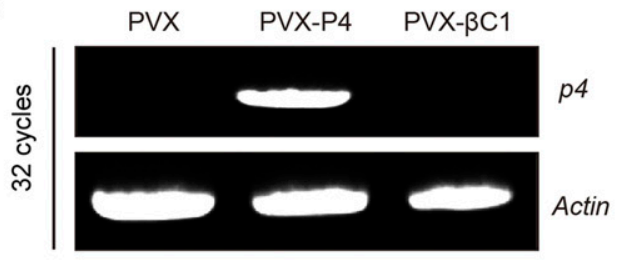

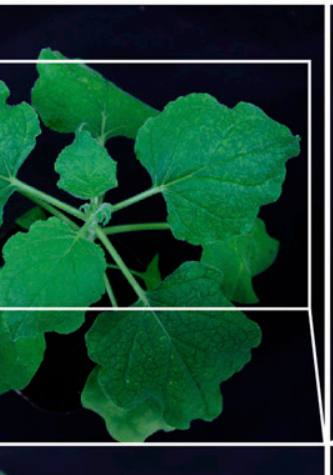

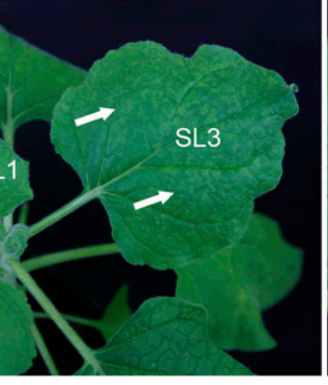

\section{(1) \\ PVX- $\beta \mathrm{C} 1$}
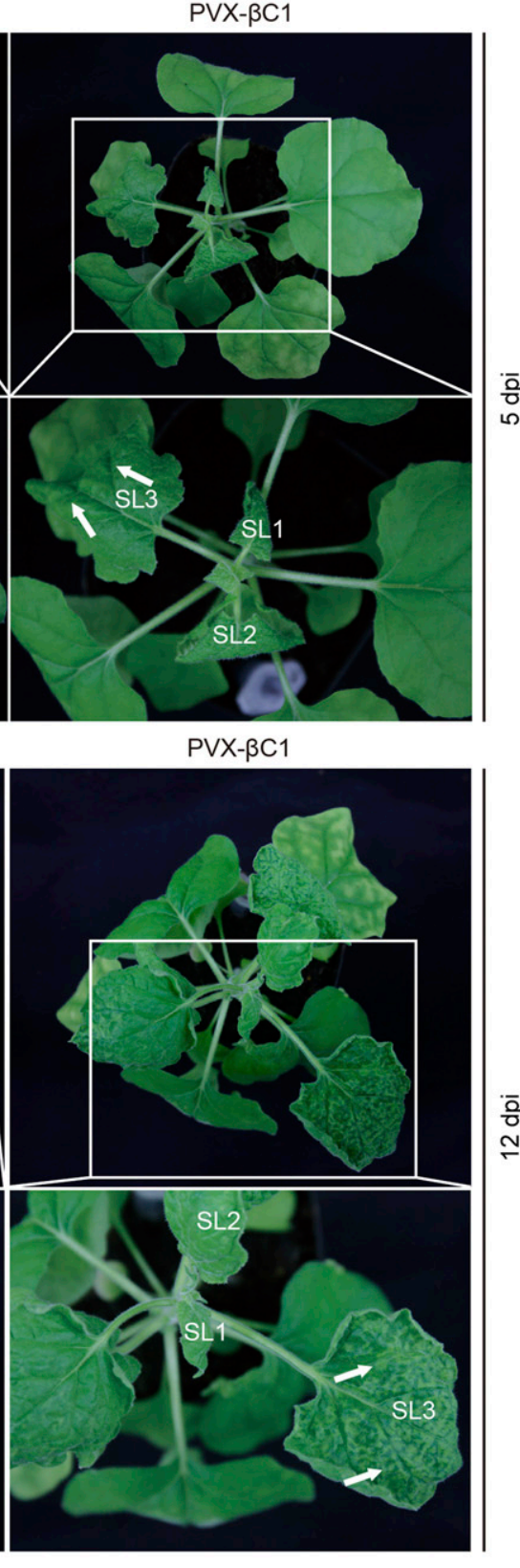

$\stackrel{\overline{0}}{\stackrel{0}{ }}$

$\stackrel{N}{\sim}$
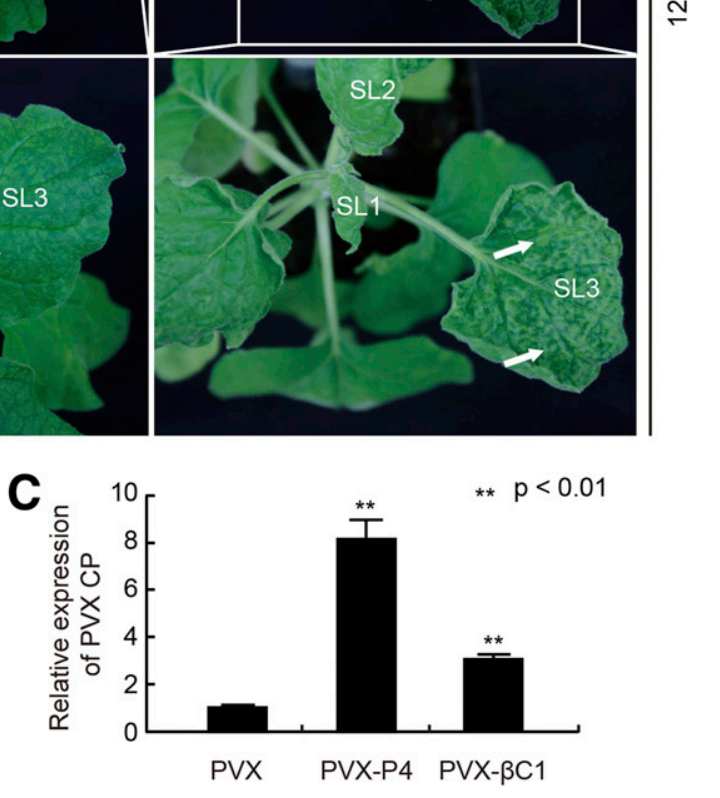

Fig. 4. Effect of rice stripe mosaic virus P4 on potato virus X (PVX) virulence in Nicotiana benthamiana. A, PVX-P4 aggravated virus-induced symptoms. Photographs were taken at 5 and 12 days postinfiltration (dpi). B, Detection of $P 4$ expression in $N$. benthamiana leaves infiltrated with Agrobacterium tumefaciens cells carrying PVX-P4 based on reverse transcription PCR. C, Relative expression of the PVX coat protein (CP) gene in three independent samples was analyzed by quantitative real-time PCR. $N b G A P D H$ was used as an internal reference. Similar results were obtained in three biological repeats. Double asterisks $(* *)$ indicate $P<0.01$, according to the $t$ test. Error bars represent the standard deviation of biological repeats. Scale bar $=2.5 \mathrm{~cm}$. 
$(99 \mathrm{~cm})$ (Fig. 5C). Furthermore, the ZH11 and E.V. plants had eight and ten tillers, respectively, whereas the $P 4$-overexpressing lines produced 26 tillers (Fig. 5D). These genetic analyses indicated that RSMV P4 is a pathogenicity factor in rice plants.

\section{DISCUSSION}

RNA silencing is an ancient eukaryotic pathway in which dsRNA triggers the destruction of related RNAs in the cell. Since its discovery, there has been an increasing number of reports indicating the RNA silencing pathway is crucial for multiple biological processes, including plant growth and development, responses to various stresses, and defenses against pathogens throughout the lifespan of host plants (Baulcombe 2004; Meins et al. 2005; Wang and Metzlaff 2005). Previous investigations of the microRNA-mediated gene silencing pathway provide abundant evidence for the regulatory functions of RNA silencing influencing plant growth and development and stress responses ( $\mathrm{Li}$ and Zhang 2016; Tang and Chu 2017; Zhang 2015). A recent study demonstrated that the miR167-mediated regulation of Auxin response factor 6 (ARF6) or $A R F 8$ expression is essential for the maternal control of embryonic development, anther growth, and seed development (Zheng et al. 2019). However, another study on RNA silencing in plants highlighted its association with defenses against viruses (Ding et al. 2004).

Although RNA silencing is an effective mechanism for protecting plants from viral infections, host-pathogen coevolution and a sophisticated arms race between viruses and host plants have resulted in viruses that produce VSRs that inhibit RNA silencing-mediated host defense responses. The GFP-based transient expression assay is useful for identifying plant virus-encoded VSRs. In this study, we applied this method to determine that the VSR encoded by RSMV is the matrix protein $\mathrm{P} 4$. However, we observed a lack of GFP signal in leaves coexpressing 35S-dsGFP and RSMV P4 at 5 dpi, whereas the fluorescence was still detectable in leaves coexpressing HC-Pro at $10 \mathrm{dpi}$. These observations imply the VSR activity of $\mathrm{P} 4$ is weaker than that of HC-Pro produced by Potyviridae species. Moreover, HC-Pro is a multifunctional component that may have other roles in addition to those that have already been established, including viral plant-to-plant transmission, polyprotein maturation, and the suppression of RNA silencing (Valli et al. 2018).
A

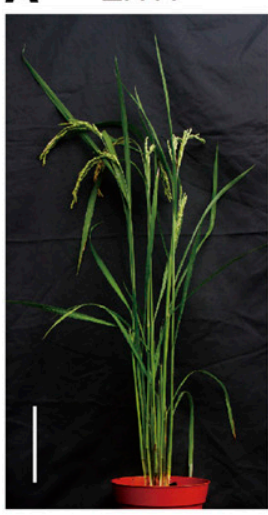

C
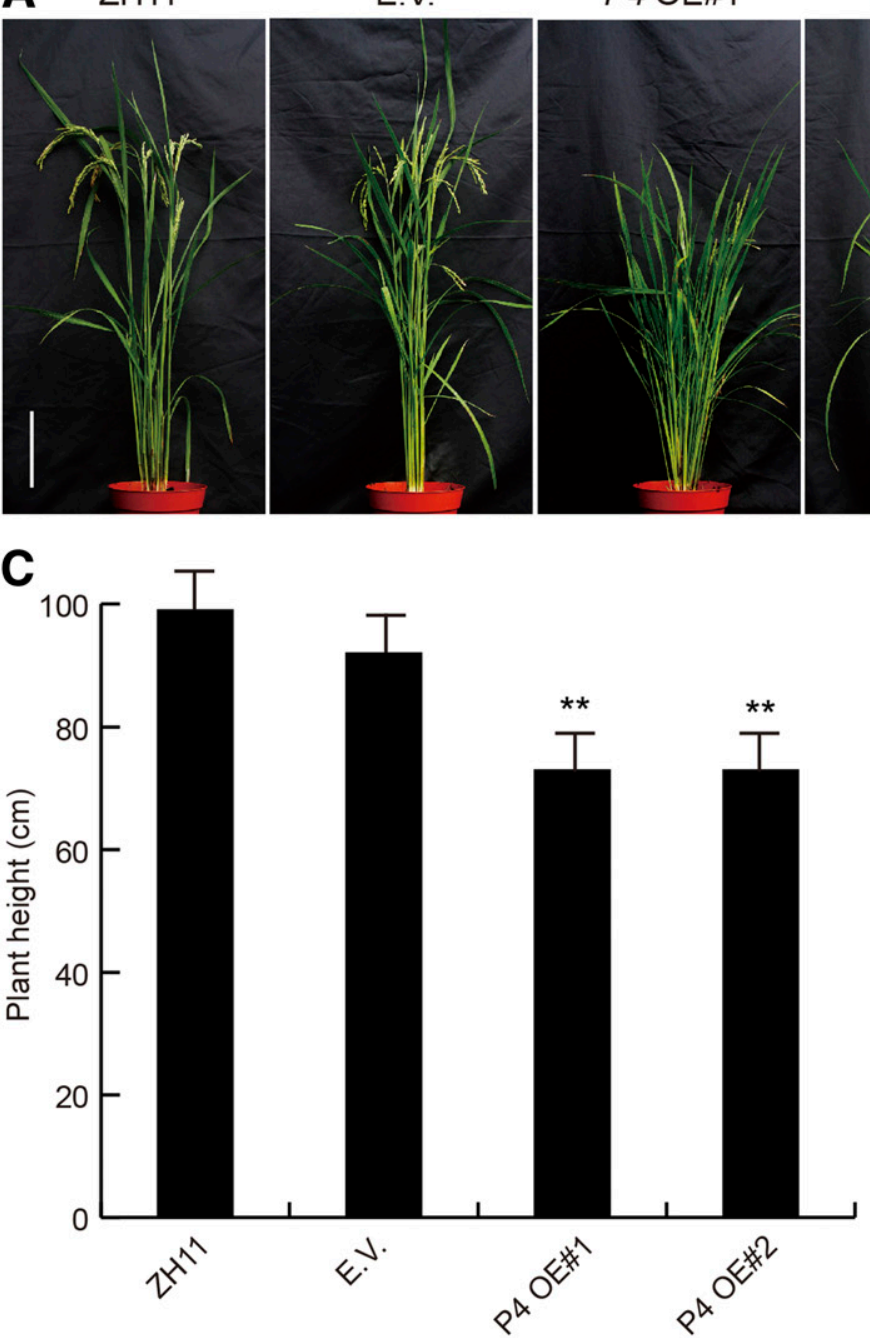

P4 OE\#2

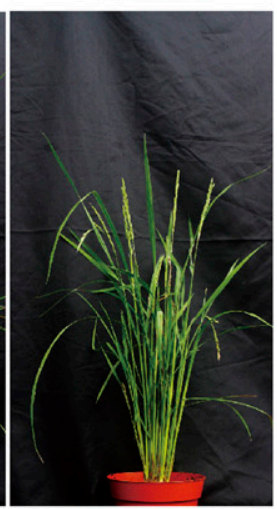

D

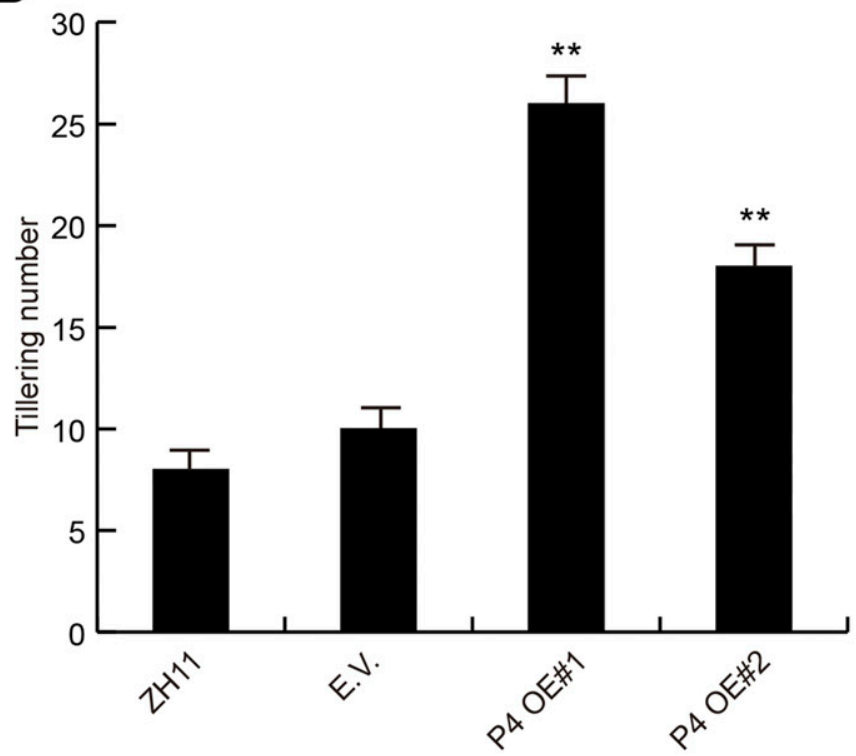

Fig. 5. Transgenic lines overexpressing rice stripe mosaic virus $P 4$ exhibit pleiotropic phenotypes affecting important agricultural traits. A, $P 4$-overexpressing lines (P4 OE-\#1 and P4 OE-\#2) exhibited slightly increased tillering and mild stunted growth. B, Confirmation of $P 4$ expression in transgenic P4overexpressing rice plants based on real-time PCR. Rice Actin1 was used as an internal reference. The presence of P4 in leaves was verified by a Western blot with an anti-P4 polyclonal antibody. Ponceau staining of the large RUBISCO subunit served as a loading control. C, Analysis of plant height. D, Analysis of tillering $(n=30)$. Double asterisks $(* *)$ indicate $P<0.01$, according to the $t$ test. Error bars represent the standard deviation of biological repeats. Scale bar $=15$ cm. 
Most VSRs are pathogenicity factors or contribute to viral infections and accumulation in host plants. Thus, a PVX-based expression assay is usually conducted to determine the pathogenicity of a VSR after it is identified in a GFP-based transient expression assay. There are three main explanations for the enhanced pathogenicity of PVX due to VSRs. First, the exacerbation of the symptoms produced by recombinant PVX viruses expressing viral VSRs is reportedly linked to an increase in the accumulation of PVX RNA in infected plants (Deng et al. 2015; Fujita et al. 2018). Second, the enhanced PVX pathogenicity is not induced by the increased accumulation of PVX RNA but by the production of VSR, which is a toxic protein that directly induces disease-like symptoms. A previous study proved that $\mathrm{p} 24$, which is a VSR produced by grapevine leafroll-associated virus 2 ( $\mathrm{Li}$ et al. 2018), elicits systemic necrosis in $N$. benthamiana when expressed from the PVX vector because of enhanced hypersensitive responses (Wang et al. 2019). Third, VSR-encoding transcripts generated from a PVX expression system are possible inducers that increase pathogenicity. Our data suggest that RSMV-encoded P4 can enhance PVX pathogenicity by increasing PVX RNA accumulation, which is consistent with the effects of $\mathrm{NaBp}$ from sweet potato chlorotic fleck virus and cysteine-rich protein from carlaviruses.

Earlier investigations suggested that VSRs from viruses belonging to different taxonomic groups are unrelated proteins controlled by diverse mechanisms at various steps of RNA silencing pathways (Csorba et al. 2015; Daròs 2017). Additionally, HC-Pro is a VSR that simultaneously targets different steps of the antiviral RNA silencing process (Valli et al. 2018). For example, HC-Pro encoded by tobacco etch virus suppresses the antiviral RNA silencing through the sequestration of vsiRNAs (Lakatos et al. 2006) and the downregulated expression of AGO1 (Várallyay and Havelda 2013). In the current study, we demonstrated that RSMV P4 can bind to SGS3 to repress antiviral RNA silencing, but $\mathrm{P} 4$ may suppress antiviral RNA silencing via other means. Incarbone et al. (2017) recently uncovered a novel RNA silencing suppression strategy that involves the transport of the mobile silencing signal into peroxisomes to disrupt plant defense. Accordingly, the suppressive effects of VSRs on antiviral RNA silencing might not be fully established. Therefore, VSRs may need to be more comprehensively functionally characterized in future studies.

An obvious feature that differentiates rice viruses from other plant viruses is that most rice viruses have a multicomponent genome that requires complex interactions with the host eukaryotic system to complete their infection, replication, transcription, translation, movement, and pathogenicity. Thus, there may be more than one VSR encoded in a rice virus genome. The increasing complexity of a virus may result in a greater number of loci targeted by the host antiviral RNA silencing pathway. To date, the RSV (Du et al. 2011; Xiong et al. 2009), RGSV (Nguyen et al. 2015; Zhang et al. 2015), RRSV (Nguyen et al. 2015; Wu et al.2010a), and RGDV (Liu et al. 2008; Wu et al. 2011) genomes have been confirmed to encode two VSRs.

In summary, RSMV-encoded P4 is a weak VSR that targets SGS3 to impair the antiviral RNA silencing pathway. Additionally, the importance of $\mathrm{P} 4$ to viral pathogenicity will need to be thoroughly investigated in future studies. The data presented herein may be useful for elucidating the RSMV infection cycle and may be relevant for the development of improved methods for controlling this pathogen.

\section{MATERIALS AND METHODS}

Plant materials, viral infection, and vectors.

The RSMV was maintained by serial transfers with Recilia dorsalis in rice plants (Oryza sativa var. Taichung Native 1) in the greenhouse at the Fujian Agriculture and Forestry University. The seeds of wild-type and transgenic (line 16c) $N$. benthamiana plants were stored in our laboratory. The seeds were germinated, and the resulting seedlings were grown in an illumination incubator at $25^{\circ} \mathrm{C}$ with a 12 -h photoperiod. The following vectors used in this study were stored in our laboratory: transient expression vectors (pEarleyGate100 [no tag], pEarleyGate101 [for a C-terminal YFP tag], pEarleyGate102 [for a C-terminal CFP tag], pEarleyGate201 [for an N-terminal hemagglutinin tag], pEarleyGate202 [for an N-terminal Flag tag], pEarleyGate203 [for an N-terminal Myc tag], pYFPN, and pYFPC), yeast expression vectors (pGBKT7 and pGADT7), and a PVX vector (pGR107).

\section{Plasmid construction.}

To complete a GFP-based transient expression assay, the fulllength P4 ORF was amplified by PCR with cDNA from the leaves of RSMV-infected rice plants and the P4-Gateway-F and P4-C-terminal Myc-Gateway-R primer pair containing 5' homologous recombination sequences. The PCR products were inserted into the entry vector pDONR221 with BP Clonase II enzyme (Invitrogen). Transformants were identified based on a PCR amplification. The recombinant plasmids were sequenced and were then digested with $M l u \mathrm{I}$ (Takara). The purified fragment containing $P 4$ was inserted into the plant transient expression vector pEarleyGate100 (to produce P4-Myc) with LR Clonase II enzyme (Invitrogen). A vector carrying the gene encoding the known VSR potyviral HC-Pro protein was used as a positive control and the original E.V. was used as a negative control. Another control vector was constructed with a mutated P4 in which the second codon (TCT) was replaced with the stop codon (TAG). The four constructs were named HC-Pro, E.V., P4-Myc, and P $\Delta 4-\mathrm{Myc}$.

To investigate the interaction between RSMV P4 and OsSGS3 (Os12g09580) in a Y2H assay, the full-length $P 4$ and OsSGS3 ORFs were amplified by PCR with the P4-Gateway-F and P4-Gateway(+stop codon)-R and the OsSGS3-Gateway-F and OsSGS3-Gateway(+stop codon)-R primer pairs, respectively. The amplified products were inserted into the yeast expression vectors pGBKT7 and pGADT7 (i.e., BD and AD, respectively) to generate the $\mathrm{BD}-\mathrm{P} 4, \mathrm{AD}-\mathrm{P} 4, \mathrm{BD}-\mathrm{OsSGS} 3$, and AD-OsSGS3 constructs.

To confirm the P4-OsSGS3 interaction with a BiFC assay and determine the subcellular localization of RSMV P4 and OsSGS3, the full-length RSMV P4 and OsSGS3 ORFs were amplified by PCR with the P4-Gateway-F and P4-Gateway (-stop codon)-R and the OsSGS3-Gateway-F and OsSGS3Gateway(-stop codon)-R primer pairs, respectively. The PCR products were inserted into pYFPN, pYFPC, pEarleyGate101, and pEarleyGate102, to prepare the pYFPN-P4, pYFPNOsSGS3, CFP-P4, and YFP-OsSGS3 constructs. A construct for the production of CFP-SV40 was generated to label nuclei.

To study the roles of RSMV P4 during viral infections in the context of plant-virus interactions, pGR107, a PVX vector, was used for RSMV $P 4$ expression. The full-length $P 4$ ORF was amplified by PCR with the P4-PVX-F and P4-PVX-R primer pair and were then cloned into pGR107, to produce the PVX-P4 construct. The empty pGR107 vector and PVX- $\beta$ C1 were used as negative and positive controls, respectively.

To generate RSMV P4-overexpressing transgenic lines, the full-length $P 4$ ORF was amplified by PCR with the P4-Transgene$\mathrm{F}$ and $\mathrm{P} 4$-Transgene- $\mathrm{R}$ primer pair and was inserted into the plant binary expression vector under the control of the rice Actinl promoter to produce the pActin $1:: P 4$ construct. Rice plants were transformed with the recombinant plasmid via the Agrobacterium tumefaciens-mediated rice genetic transformation system by the Biorun company to obtain transgenic P4-overexpressing lines. 
Details regarding the primers used for constructing recombinant plasmids are provided in Supplementary Table S1.

\section{A. tumefaciens infiltration, GFP imaging, and confocal microscopy.}

The A. tumefaciens infiltration was completed as previously described (Wu et al. 2011). Briefly, all plant expression constructs were separately inserted into A. tumefaciens GV3101 cells. Cultures of transformed GV3101 cells were grown in Luria Bertani medium containing rifampicin $(50 \mathrm{mg} / \mathrm{ml})$ and kanamycin $(50 \mathrm{mg} / \mathrm{ml})$ at $28^{\circ} \mathrm{C}$ for $48 \mathrm{~h}$. Transformants were identified based on colony PCR. The cells of a GV3101 culture for each recombinant plasmid were resuspended in infiltration medium ( $5 \mathrm{mg}$ of glucose per milliliter, $10 \mathrm{mM}$ MES, $10 \mathrm{mM}$ $\mathrm{MgCl}_{2}$, and $200 \mathrm{mM}$ acetosyringone) for an optical density at $600 \mathrm{~nm}\left(\mathrm{OD}_{600}\right)$ of 0.8 . A GFP-based transient expression assay was conducted with 4-week-old transgenic $N$. benthamiana line $16 \mathrm{c}$ plants. The A. tumefaciens cells containing E.V., P4-Myc, $\mathrm{P} \Delta 4-\mathrm{Myc}$, or HC-Pro were mixed with the cells of a strain expressing ssGFP or dsGFP at a volume ratio of $1: 1$ for the coinfiltration of $N$. benthamiana line $16 \mathrm{c}$ leaf epidermal cells. The GFP fluorescence in the coinfiltrated leaves was detected with a hand-held UV light (Black Ray model B 100A, UV Products) and was photographed with the Nikon D70 digital camera at 1 and 3 dpi.

A BiFC assay was completed with 4- to 6-week-old N. benthamiana plants. Specifically, A. tumefaciens cells transformed with pYFPN-P4/pYFPC-OsSGS3, pYFPN-P4/pYFPC, pYFPN/pYFPCOsSGS3, and $\mathrm{pYFPN} / \mathrm{pYFPC}$ were mixed at a volume ratio of $1: 1$ for an inoculation of $N$. benthamiana leaf epidermal cells. Additionally, pYFPN-P4/pYFPC, pYFPN/pYFPC-OsSGS3, and $\mathrm{pYFPN} / \mathrm{pYFPC}$ were used as negative controls. For the subcellular colocalization assay, A. tumefaciens cells transformed with CFP-P4/YFP-OsSGS3 were mixed as described above and were used to inoculate $N$. benthamiana leaf epidermal cells. To visualize the P4 and OsSGS3 localization patterns, $N$. benthamiana leaf epidermal cells were transformed with A. tumefaciens cells carrying CFP-P4 or YFP-OsSGS3. Moreover, CFP-SV40 was used as a nuclear localization marker. The infiltrated $N$. benthamiana epidermal cells were examined for fluorescence with the Leica DS6000 confocal microscope at 2 dpi.

For protein degradation assays, the A. tumefaciens cells transformed with the Flag-P4 and Myc-OsSGS3 constructs were resuspended in infiltration medium for an $\mathrm{OD}_{600}$ of 3.6 and were then mixed together to produce the indicated concentration. Additionally, GFP was used as a negative control.

\section{Y2H assay.}

A Gal4-based $\mathrm{Y} 2 \mathrm{H}$ system was used to detect the interaction between RSMV P4 and OsSGS3. The plasmid pairs AD-P4 and BD-OsSGS3 and AD-OsSGS3 and BD-P4 were used to cotransform $100 \mu \mathrm{l}$ of freshly prepared Y2HGold competent cells with the help of $5 \mu$ l of herring carrier DNA (Takara), according to the lithium acetate method. Yeast cells cotransformed with $\mathrm{AD}-\mathrm{P} 4$ and $\mathrm{BD}, \mathrm{AD}$ and $\mathrm{BD}-\mathrm{OsSGS3}, \mathrm{AD}$ OsSGS3 and BD, AD and BD-P4, and AD-T and BD-Lam were used as negative controls, whereas cells with AD-T and BD-53 served as the positive control. Transformants were uniformly plated on the agar-solidified double dropout (DDO) medium $\mathrm{SD} /-\mathrm{Leu} /-\mathrm{Trp}$. Plates were incubated in a constant temperature incubator at $30^{\circ} \mathrm{C}$. Yeast cotransformants that grew on the DDO medium were transferred to plates containing the agarsolidified QDO medium SD/-Leu/-Trp/-His/-Ade. The detected interactions were checked in an $\alpha$-galactosidase activity assay on QDO medium containing the $\alpha$-galactosidase substrate X- $\alpha$-gal.

\section{Trypan blue and DAB staining assays.}

Superoxide and cell death were detected with DAB and trypan blue staining, respectively, as previously described (Liu et al. 2016). For DAB staining, whole $N$. benthamiana leaves were infiltrated with a $1 \mathrm{mg} / \mathrm{ml}$ DAB solution ( $\mathrm{pH}$ 5.7) and were then incubated overnight (almost $8 \mathrm{~h}$ ) in darkness. Leaves were then de-stained three times with $95 \%$ ethanol. For trypan blue staining, whole $N$. benthamiana leaves were boiled in a lactophenol-ethanol trypan blue solution $(10 \mathrm{ml}$ of lactic acid, $10 \mathrm{ml}$ of glycerol, $10 \mathrm{~g}$ of phenol, $30 \mathrm{ml}$ of absolute ethanol, and $10 \mathrm{mg}$ of trypan blue dissolved in $10 \mathrm{ml}$ of distilled water) for $5 \mathrm{~min}$, after which the leaves were maintained overnight at room temperature. The leaves were then de-stained with $2.5 \mathrm{~g}$ of chloral hydrate per milliliter in distilled water. Analyses were independently completed three times.

\section{RNA extraction, reverse transcription PCR, and qRT-PCR analysis.}

Total RNA was extracted from the leaves of rice plants or $N$. benthamiana plants with the Plant RNA kit (Omega), after which first-strand cDNA was synthesized with the First Strand cDNA synthesis kit (Toyobo Co., Ltd.). To confirm the P4 expression in $P 4$-overexpressing transgenic rice plants, reverse transcription PCR was conducted. To analyze GFP, $P V X$, and $C P$ expression levels in $N$. benthamiana and SGS3, DCL2, $D C L 3, D C L 4, R D R 1$, and $R D R 2$ expression levels in rice in a qRT-PCR assay, the StarScript II First-strand cDNA synthesis mix with gDNA remover kit (GenStar) was used to synthesize cDNA. The qRT-PCR assay was performed with the RealStar Green Fast mixture (GenStar). Details regarding the qRT-PCR primers are listed in Supplementary Table S1.

\section{Protein extraction and Western blot analysis.}

Proteins were extracted from $100 \mathrm{mg}$ of leaf samples with $100 \mu \mathrm{l}$ of extraction buffer $(50 \mathrm{mM}$ Tris- $\mathrm{HCl}$ [pH 6.8], $9 \mathrm{M}$ urea, $4.5 \%$ sodium dodecyl sulfate [SDS], and $7.5 \% \beta$-mercaptoethanol). The crude extracts were boiled at $98^{\circ} \mathrm{C}$ for $10 \mathrm{~min}$ and were then centrifuged at $12,000 \mathrm{rpm}$ for $10 \mathrm{~min}$ at $4^{\circ} \mathrm{C}$. The proteins in the supernatant were separated in SDSpolyacrylamide electrophoresis gels, which were also used for immunoblotting assays, as previously described (Wu et al. 2015). Anti-Myc, anti-Flag, anti-GFP, and anti-actin monoclonal antibodies (Abmart) were used for the Western blot analysis to verify the production of the proteins of interest in transient expression systems. Polyclonal anti-P4 antibodies were used for the Western blot analysis to verify the production of RSMV P4 in transgenic lines.

\section{Statistical analysis.}

Data underwent a one-way analysis of variance with Fisher's least significant difference test. A $P$ value $\leq 0.05$ was used as a threshold for identifying significant differences. All analyses were performed with the ORIGIN 8.0 program.

\section{ACKNOWLEDGMENTS}

We thank L. Bianji for editing the English text of a draft of this manuscript.

\section{LITERATURE CITED}

Ahlquist, P. 2006. Parallels among positive-strand RNA viruses, reversetranscribing viruses and double-stranded RNA viruses. Nat. Rev. Microbiol. 4:371-382.

Baulcombe, D. 2004. RNA silencing in plants. Nature 431:356-363.

Blevins, T., Rajeswaran, R., Shivaprasad, P. V., Beknazariants, D., SiAmmour, A., Park, H. S., Vazquez, F., Robertson, D., Meins, F., Jr., Hohn, T., and Pooggin, M. M. 2006. Four plant Dicers mediate viral small RNA biogenesis and DNA virus induced silencing. Nucleic Acids Res. 34:6233-6246. 
Bouché, N., Lauressergues, D., Gasciolli, V., and Vaucheret, H. 2006. An antagonistic function for Arabidopsis DCL2 in development and a new function for DCL4 in generating viral siRNAs. EMBO J. 25:3347-3356.

Carbonell, A., and Carrington, J. C. 2015. Antiviral roles of plant ARGONAUTES. Curr. Opin. Plant Biol. 27:111-117.

Cheng, X., and Wang, A. 2016. The potyvirus silencing suppressor protein VPg mediates degradation of SGS3 via ubiquitination and autophagy pathways. J. Virol. 91:e01478-16.

Csorba, T., Kontra, L., and Burgyan, J. 2015. Viral silencing suppressors: Tools forged to fine-tune host-pathogen coexistence. Virology 479-480: 85-103.

Daròs, J. A. 2017. Viral suppressors: Combatting RNA silencing. Nat. Plants 3:17098.

Deleris, A., Gallego-Bartolome, J., Bao, J., Kasschau, K. D., Carrington, J. C., and Voinnet, O. 2006. Hierarchical action and inhibition of plant Dicer-like proteins in antiviral defense. Science 313:68-71.

Deng, X. G., Peng, X. J., Zhu, F., Chen, Y. J., Zhu, T., Qin, S. B., Xi, D. H., and Lin, H. H. 2015. A critical domain of sweet potato chlorotic fleck virus nucleotide-binding protein ( $\mathrm{NaBp}$ ) for RNA silencing suppression, nuclear localization and viral pathogenesis. Mol. Plant Pathol. 16:365-375.

Ding, S. W., Li, H., Lu, R., Li, F., and Li, W. X. 2004. RNA silencing: A conserved antiviral immunity of plants and animals. Virus Res. 102: 109-115.

Ding, S. W., and Voinnet, O. 2007. Antiviral immunity directed by small RNAs. Cell 130:413-426.

Donaire, L., Barajas, D., Martínez-García, B., Martínez-Priego, L., Pagán, I., and Llave, C. 2008. Structural and genetic requirements for the biogenesis of tobacco rattle virus-derived small interfering RNAs. J. Virol. 82:5167-5177.

Donaire, L., Wang, Y., Gonzalez-Ibeas, D., Mayer, K. F., Aranda, M. A., and Llave, C. 2009. Deep-sequencing of plant viral small RNAs reveals effective and widespread targeting of viral genomes. Virology 392: 203-214.

Du, Q. S., Duan, C. G., Zhang, Z. H., Fang, Y. Y., Fang, R. X., Xie, Q., and Guo, H. S. 2007. DCL4 targets cucumber mosaic virus satellite RNA at novel secondary structures. J. Virol. 81:9142-9151.

Du, Z., Xiao, D., Wu, J., Jia, D., Yuan, Z., Liu, Y., Hu, L., Han, Z., Wei, T., Lin, Q., Wu, Z., and Xie, L. 2011. p2 of Rice stripe virus (RSV) interacts with OsSGS3 and is a silencing suppressor. Mol. Plant Pathol. 12: 808-814.

Fujita, N., Komatsu, K., Ayukawa, Y., Matsuo, Y., Hashimoto, M., Netsu, O., Teraoka, T., Yamaji, Y., Namba, S., and Arie, T. 2018. N-terminal region of cysteine-rich protein (CRP) in carlaviruses is involved in the determination of symptom types. Mol. Plant Pathol. 19:180-190.

Garcia-Ruiz, H., Takeda, A., Chapman, E. J., Sullivan, C. M., Fahlgren, N., Brempelis, K. J., and Carrington, J. C. 2010. Arabidopsis RNAdependent RNA polymerases and dicer-like proteins in antiviral defense and small interfering RNA biogenesis during Turnip mosaic virus infection. Plant Cell 22:481-496.

Glick, E., Zrachya, A., Levy, Y., Mett, A., Gidoni, D., Belausov, E., Citovsky, V., and Gafni, Y. 2008. Interaction with host SGS3 is required for suppression of RNA silencing by tomato yellow leaf curl virus V2 protein. Proc. Natl. Acad. Sci. U.S.A. 105:157-161.

Guo, H., Song, X., Xie, C., Huo, Y., Zhang, F., Chen, X., Geng, Y., and Fang, R. 2013. Rice yellow stunt rhabdovirus protein 6 suppresses systemic RNA silencing by blocking RDR6-mediated secondary siRNA synthesis. Mol. Plant-Microbe Interact. 26:927-936.

Hemmes, H., Kaaij, L., Lohuis, D., Prins, M., Goldbach, R., and Schnettler, E. 2009. Binding of small interfering RNA molecules is crucial for RNA interference suppressor activity of rice hoja blanca virus NS3 in plants. J. Gen. Virol. 90:1762-1766.

Henderson, I. R., Zhang, X., Lu, C., Johnson, L., Meyers, B. C., Green, P. J., and Jacobsen, S. E. 2006. Dissecting Arabidopsis thaliana DICER function in small RNA processing, gene silencing and DNA methylation patterning. Nat. Genet. 38:721-725.

Incarbone, M., Zimmermann, A., Hammann, P., Erhardt, M., Michel, F., and Dunoyer, P. 2017. Neutralization of mobile antiviral small RNA through peroxisomal import. Nat. Plants 3:17094.

Jiang, L., Wei, C., and Li, Y. 2012. Viral suppression of RNA silencing. Sci. China Life Sci. 55:109-118.

Johansen, L. K., and Carrington, J. C. 2001. Silencing on the spot. Induction and suppression of RNA silencing in the Agrobacterium-mediated transient expression system. Plant Physiol. 126:930-938.

Karran, R. A., and Sanfaçon, H. 2014. Tomato ringspot virus coat protein binds to ARGONAUTE 1 and suppresses the translation repression of a reporter gene. Mol. Plant-Microbe Interact. 27:933-943.

Kasschau, K. D., Fahlgren, N., Chapman, E. J., Sullivan, C. M., Cumbie, J. S., Givan, S. A., and Carrington, J. C. 2007. Genome-wide profiling and analysis of Arabidopsis siRNAs. PLoS Biol. 5:e57.
Kumakura, N., Takeda, A., Fujioka, Y., Motose, H., Takano, R., and Watanabe, Y. 2009. SGS3 and RDR6 interact and colocalize in cytoplasmic SGS3/RDR6-bodies. FEBS Lett. 583:1261-1266.

Lacombe, S., Bangratz, M., Vignols, F., and Brugidou, C. 2010. The rice yellow mottle virus $\mathrm{P} 1$ protein exhibits dual functions to suppress and activate gene silencing. Plant J. 61:371-382.

Lakatos, L., Csorba, T., Pantaleo, V., Chapman, E. J., Carrington, J. C., Liu, Y. P., Dolja, V. V., Calvino, L. F., López-Moya, J. J., and Burgyán, J. 2006. Small RNA binding is a common strategy to suppress RNA silencing by several viral suppressors. EMBO J. 25:2768-2780.

Li, C., and Zhang, B. 2016. MicroRNAs in control of plant development. J. Cell. Physiol. 231:303-313.

Li, F., and Ding, S. W. 2006. Virus counterdefense: Diverse strategies for evading the RNA-silencing immunity. Annu. Rev. Microbiol. 60:503-531.

Li, F., and Wang, A. 2019. RNA-targeted antiviral immunity: More than just RNA silencing. Trends Microbiol. 27:792-805.

Li, M., Zhang, J., Feng, M., Wang, X., Luo, C., Wang, Q., and Cheng, Y. 2018. Characterization of silencing suppressor p24 of Grapevine leafroll-associated virus 2. Mol. Plant Pathol. 19:355-368.

Liu, F. X., Zhao, Q., Ruan, X., He, Y., and Li, H. 2008. Suppressor of RNA silencing encoded by Rice gall dwarf virus genome segment 11. Chin. Sci. Bull. 53:362-369.

Liu, Z. Q., Liu, Y. Y., Shi, L. P., Yang, S., Shen, L., Yu, H. X., Wang, R. Z., Wen, J. Y., Tang, Q., Hussain, A., Khan, M. I., Hu, J., Liu, C. L., Zhang, Y. W., Cheng, W., and He, S. L. 2016. SGT1 is required in PcINF1/SRC2-1 induced pepper defense response by interacting with SRC2-1. Sci. Rep. 6:21651.

Llave, C. 2010. Virus-derived small interfering RNAs at the core of plantvirus interactions. Trends Plant Sci. 15:701-707.

Llave, C., Kasschau, K. D., and Carrington, J. C. 2000. Virus-encoded suppressor of posttranscriptional gene silencing targets a maintenance step in the silencing pathway. Proc. Natl. Acad. Sci. U.S.A. 97:13401-13406.

Lu, Y., Zhang, J., Xiong, R., Xu, Q., and Zhou, Y. 2011. Identification of an RNA silencing suppressor encoded by southern rice black-streaked dwarf virus S6. Sci. Agric. Sinica 44:2909-2917.

Margis, R., Fusaro, A. F., Smith, N. A., Curtin, S. J., Watson, J. M., Finnegan, E. J., and Waterhouse, P. M. 2006. The evolution and diversification of Dicers in plants. FEBS Lett. 580:2442-2450.

Meins, F., Jr., Si-Ammour, A., and Blevins, T. 2005. RNA silencing systems and their relevance to plant development. Annu. Rev. Cell Dev. Biol. 21: 297-318.

Mérai, Z., Kerényi, Z., Kertész, S., Magna, M., Lakatos, L., and Silhavy, D. 2006. Double-stranded RNA binding may be a general plant RNA viral strategy to suppress RNA silencing. J. Virol. 80:5747-5756.

Molnár, A., Csorba, T., Lakatos, L., Várallyay, E., Lacomme, C., and Burgyán, J. 2005. Plant virus-derived small interfering RNAs originate predominantly from highly structured single-stranded viral RNAs. J. Virol. 79:7812-7818

Nguyen, T. D., Lacombe, S., Bangratz, M., Ta, H. A., Vinh, N., Gantet, P., and Brugidou, C. 2015. P2 of rice grassy stunt virus (RGSV) and p6 and p9 of rice ragged stunt virus (RRSV) isolates from Vietnam exert suppressor activity on the RNA silencing pathway. Virus Genes 51: 267-275.

Okano, Y., Senshu, H., Hashimoto, M., Neriya, Y., Netsu, O., Minato, N., Yoshida, T., Maejima, K., Oshima, K., Komatsu, K., Yamaji, Y., and Namba, S. 2014. In planta recognition of a double-stranded RNA synthesis protein complex by a potexviral RNA silencing suppressor. Plant Cell 26:2168-2183.

Peragine, A., Yoshikawa, M., Wu, G., Albrecht, H. L., and Poethig, R. S. 2004. SGS3 and SGS2/SDE1/RDR6 are required for juvenile development and the production of trans-acting siRNAs in Arabidopsis. Genes Dev. 18:2368-2379.

Qi, X., Bao, F. S., and Xie, Z. 2009. Small RNA deep sequencing reveals role for Arabidopsis thaliana RNA-dependent RNA polymerases in viral siRNA biogenesis. PLoS One 4:e4971.

Ren, B., Guo, Y., Gao, F., Zhou, P., Wu, F., Meng, Z., Wei, C., and Li, Y. 2010. Multiple functions of rice dwarf phytoreovirus Pns10 in suppressing systemic RNA silencing. J. Virol. 84:12914-12923.

Schwach, F., Vaistij, F. E., Jones, L., and Baulcombe, D. C. 2005. An RNAdependent RNA polymerase prevents meristem invasion by potato virus $\mathrm{X}$ and is required for the activity but not the production of a systemic silencing signal. Plant Physiol. 138:1842-1852.

Shen, M., Xu, Y., Jia, R., Zhou, X., and Ye, K. 2010. Size-independent and noncooperative recognition of dsRNA by the rice stripe virus RNA silencing suppressor NS3. J. Mol. Biol. 404:665-679.

Silhavy, D., Molnár, A., Lucioli, A., Szittya, G., Hornyik, C., Tavazza, M., and Burgyán, J. 2002. A viral protein suppresses RNA silencing and binds silencing-generated, 21- to 25-nucleotide double-stranded RNAs. EMBO J. 21:3070-3080. 
Simón-Mateo, C., and García, J. A. 2011. Antiviral strategies in plants based on RNA silencing. Biochim. Biophys. Acta 1809:722-731.

Tang, J., and Chu, C. 2017. MicroRNAs in crop improvement: Fine-tuners for complex traits. Nat. Plants 3:17077.

Valli, A. A., Gallo, A., Rodamilans, B., López-Moya, J. J., and García, J. A. 2018. The HCPro from the Potyviridae family: An enviable multitasking Helper Component that every virus would like to have. Mol. Plant Pathol. 19:744-763.

Várallyay, E., and Havelda, Z. 2013. Unrelated viral suppressors of RNA silencing mediate the control of ARGONAUTE1 level. Mol. Plant Pathol. 14:567-575.

Wang, M. B., and Metzlaff, M. 2005. RNA silencing and antiviral defense in plants. Curr. Opin. Plant Biol. 8:216-222.

Wang, X., Luo, C., Xu, Y., Zhang, C., Bao, M., Dou, J., Wang, Q., and Cheng, Y. 2019. Expression of the p24 silencing suppressor of Grapevine leafroll-associated virus 2 from Potato virus X or Barley stripe mosaic virus vector elicits hypersensitive responses in Nicotiana benthamiana. Plant Physiol. Biochem. 142:34-42.

Weinheimer, I., Haikonen, T., Ala-Poikela, M., Moser, M., Streng, J., Rajamäki, M. L., and Valkonen, J. P. 2016. Viral RNase3 co-localizes and interacts with the antiviral defense protein SGS3 in plant cells. PLoS One 11:e0159080.

Wu, J., Du, Z., Wang, C., Cai, L., Hu, M., Lin, Q., Wu, Z., Li, Y., and Xie, L. 2010a. Identification of Pns6, a putative movement protein of RRSV, as a silencing suppressor. Virol. J. 7:335.

Wu, J., Wang, C., Du, Z., Cai, L., Hu, M., Wu, Z., Li, Y., and Xie, L. 2011. Identification of Pns12 as the second silencing suppressor of rice gall dwarf virus. Sci. China Life Sci. 54:201-208.

Wu, J., Yang, Z., Wang, Y., Zheng, L., Ye, R., Ji, Y., Zhao, S., Ji, S., Liu, R., Xu, L., Zheng, H., Zhou, Y., Zhang, X., Cao, X., Xie, L., Wu, Z., Qi, Y., and Li, Y. 2015. Viral-inducible Argonaute18 confers broad-spectrum virus resistance in rice by sequestering a host microRNA. eLife 4:e05733.

Wu, Q., Wang, X., and Ding, S. W. 2010b. Viral suppressors of RNA-based viral immunity: Host targets. Cell Host Microbe 8:12-15.

Xie, Z., Fan, B., Chen, C., and Chen, Z. 2001. An important role of an inducible RNA-dependent RNA polymerase in plant antiviral defense. Proc. Natl. Acad. Sci. U.S.A. 98:6516-6521.
Xiong, R., Wu, J., Zhou, Y., and Zhou, X. 2009. Characterization and subcellular localization of an RNA silencing suppressor encoded by rice stripe tenuivirus. Virology 387:29-40.

Yang, S. J., Carter, S. A., Cole, A. B., Cheng, N. H., and Nelson, R. S. 2004. A natural variant of a host RNA-dependent RNA polymerase is associated with increased susceptibility to viruses by Nicotiana benthamiana. Proc. Natl. Acad. Sci. U.S.A. 101:6297-6302.

Yang, X., Huang, J., Liu, C., Chen, B., Zhang, T., and Zhou, G. 2017. Rice stripe mosaic virus, a novel cytorhabdovirus infecting rice via leafhopper transmission. Front. Microbiol. 7:2140.

Yoshikawa, M., Iki, T., Tsutsui, Y., Miyashita, K., Poethig, R. S., Habu, Y., and Ishikawa, M. 2013. 3' fragment of miR173-programmed RISCcleaved RNA is protected from degradation in a complex with RISC and SGS3. Proc. Natl. Acad. Sci. U.S.A. 110:4117-4122.

Zhang, B. 2015. MicroRNA: A new target for improving plant tolerance to abiotic stress. J. Exp. Bot. 66:1749-1761.

Zhang, C., Liu, X. J., Wu, K. C., Zheng, L. P., Ding, Z. M., Li, F., Zou, P., Yang, L., Wu, J. G., and Wu, Z. J. 2015. Rice grassy stunt virus nonstructural protein $\mathrm{p} 5$ serves as a viral suppressor of RNA silencing and interacts with nonstructural protein p3. Arch. Virol. 160: 2769-2779.

Zhang, L., Wang, Z., Wang, X., Li, D., Han, C., Zhai, Y., and Yu, J. 2005. Two virus-encoded RNA silencing suppressors, P14 of beet necrotic yellow vein virus and S6 of rice black streak dwarf virus. Chin. Sci. Bull. 50:305-310.

Zhang, X., Yuan, Y. R., Pei, Y., Lin, S. S., Tuschl, T., Patel, D. J., and Chua, N. H. 2006. Cucumber mosaic virus-encoded 2b suppressor inhibits Arabidopsis Argonaute1 cleavage activity to counter plant defense. Genes Dev. 20:3255-3268.

Zhao, P., Sun, X., Li, P., Sun, J., Yue, Y., Wei, J., Wei, T., and Jia, D. 2019. Infection characteristics of rice stripe mosaic virus in the body of the vector leafhoppers. Front. Microbiol. 9:3258.

Zheng, L., Nagpal, P., Villarino, G., Trinidad, B., Bird, L., Huang, Y., and Reed, J. W. 2019. miR167 limits anther growth to potentiate anther dehiscence. Development 146:dev174375. 